\title{
Gastos Públicos em Infraestrutura e em Capital Humano como forma de Promoção do Crescimento Pró-Pobre nos Estados Brasileiros
}

\section{Public Expenditure on Infrastructure and Human Capital as a form of Promotion of Pro-Poor Growth in the Brazilian States}

\author{
Aline Cristina Cruz* \\ Daniela Almeida Raposo Torres** \\ Erly Cardoso Teixeira***
}

\begin{abstract}
Resumo: Este estudo avalia a efetividade dos gastos públicos em capital humano e em infraestrutura física como forma de promover o crescimento econômico própobre nos estados brasileiros no período 1995-2008. Para tanto, realizou-se a estimação de um sistema de equações com variáveis instrumentais a partir do Método dos Momentos Generalizados (GMM). Os resultados comprovam a eficácia dos dispêndios governamentais em educação, saúde e em transporte rodoviário, no que concerne aos avanços obtidos nos estoques desses tipos de capital humano e físico. Atesta-se ainda a importância desse modelo de política pública para aumentar o nível de emprego na economia. Face ao exposto, comprovada a capacidade da elevação do rendimento per capita de reduzir o contingente populacional em condições de pobreza em cada estado, confirma-se a eficácia dos gastos públicos, aqui analisados como instrumentos de promoção de crescimento pró-pobre nos estados do Brasil.
\end{abstract}

Palavras-chave: Gastos públicos. Crescimento pró-pobre. Estados brasileiros.

Abstract: This paper evaluates the effectiveness of public expenditures in human capital and physical infrastructure to promote pro-poor economic growth in Brazilian states, from 1995 to 2008. For this, a system of equations with instrumental variables was estimated using the Generalized Moments Method (GMM). The results prove the efficacy of the governmental expenses in education, health and roads related to the advances of this kind of stocks of human and physical capital. The importance of this type of public politics for increasing the level of employment was proved too. The main result is the definition of the indirect linkage between these categories of public expenditure and the state economic growth by elevation of per capita income and the reduction of poverty in each state, analyzed here as instruments of promotion of propoor economic.

\footnotetext{
* Doutora em Economia Aplicada pela Universidade Federal de Viçosa (UFV). Professora do Departamento de Ciências Econômicas da Universidade Federal de São João del Rei. E-mail: alinecruz@ufsj.edu.br

** Doutora em Economia Regional pelo Centro de Desenvolvimento e Planejamento Regional (Cedeplar) da Universidade Federal de Minas Gerais (UFMG). Professora do Departamento de Ciências Econômicas da Universidade Federal de São João del Rei. E-mail: daniraposo@ufsj.edu.br

*** Doutor em Agricultural Economics pela Purdue University, Estados Unidos. Professor do Departamento de Economia Rural da UFV. E-mail: teixeira@ufv.br
} 
Keywords: Public expenditure. Pro-poor growth. Brazilian states.

JEL Classification: $\mathrm{C} 3$; O15; O4.

\section{Introdução}

Nas últimas décadas, apesar dos avanços, o Brasil ainda mantém a característica de grande desigualdade na distribuição de renda e de elevados níveis de pobreza. Prevalece o desafio histórico de combate à exclusão social, que afeta parte significativa da população sem acesso às condições mínimas de dignidade e cidadania. Em 2009, de acordo com informações do Instituto Brasileiro de Geografia e Estatística (IBGE, 2009), o percentual de pessoas em domicílios com renda per capita inferior à linha de pobreza era de $21,5 \%$, sendo que $14 \%$ delas se encontravam em situação de pobreza e 7\% eram classificadas como indigentes. Tais números provam que o patamar de pobreza ainda é muito elevado e inadmissível, principalmente se comparado às nações com renda per capita mensal similar à do Brasil (R\$ 755,72).

Dessa perspectiva, entre os fatores para identificar a pobreza, têm-se a escassez e a desigualdade na distribuição de recursos. No Brasil, a renda média é de $R \$ 755,72$, que é muito superior à linha de pobreza, o que corrobora a alta concentração de renda no país. Na análise inter-regional da incidência de pobreza no Brasil, as regiões Nordeste e Sudeste destacam-se, em termos absolutos, quanto ao contingente de indivíduos considerados pobres e extremamente pobres. No ano de 2009, as regiões Sudeste e Nordeste possuíam 9.017e 20.976 pessoas em condição de pobreza, cabendo destacar que o número de indigentes no Nordeste correspondia a $60 \%$ do total do país. Em termos relativos, a região Norte possui 33,68\% da população em condições de pobreza, enquanto na região Nordeste a parcela de indivíduos em domicílios com renda per capita inferior à linha de pobreza é de 40,70\%.

Entre as formas de buscar amenizar o grave problema da pobreza ligada à renda, destaca-se a possibilidade de aumento dos rendimentos dos pobres, seja via crescimento econômico (aumento geral da renda) ou pela queda de desigualdade de renda (BARROS et al., 2007). No entanto, a alta concentração de renda é um obstáculo adicional aos policymakers ao reduzir os efeitos positivos das políticas pró-crescimento. Assim, a solução é priorizar as políticas de longo prazo de crescimento sustentado, visto que medidas de cunho apenas redistributivo são, exclusivamente, mais eficientes no curto prazo (BOURGUIGNON, 2003).

Sobre o perfil atual da política econômica brasileira, este tem como norte, principalmente, os mecanismos de transferência de renda (Programa Bolsa Família) e medidas para aceleração do crescimento, a exemplo dos Programas de Ace- 
leração do Crescimento I e II. Do ponto de vista dos gastos públicos em infraestrutura social, têm-se as categorias de infraestrutura e de capital humano. A despeito dos dispêndios do governo em capital físico, o que se tem observado é sua acentuada redução desde os anos oitenta, década em que o Brasil enfrentou baixas taxas de crescimento do PIB, processo inflacionário, contração fiscal e dificuldades nas contas externas. No que diz respeito aos recursos para capital humano, há ainda muito que se fazer, apesar das metas cumpridas quanto à frequência escolar. $\mathrm{O}$ que se denota é que esses gastos permanecem como ineficientes perante a busca da qualidade do ensino. Problemas estruturais como o atraso escolar, o elevado índice de analfabetismo funcional e a baixa escolaridade média do cidadão brasileiro são ainda obstáculos ao desenvolvimento econômico nacional, o que requer investimentos adicionais desde a educação primária até o ensino superior.

Dentro dessa temática, na literatura empírica e teórica há muitos trabalhos que investigam a eficácia e/ou eficiência do Estado na promoção do crescimento e do bem-estar da sociedade. Outros focam componentes particulares dos gastos governamentais que podem afetar a produtividade do setor privado e o crescimento econômico, como os dispêndios em capital físico e humano. No trabalho de Cruz et al. (2010), a partir da estimação de um sistema de equações,são apontados os efeitos diretos e indiretos das despesas públicas em educação, saúde, estradas e energia sobre o PIB per capita, a produtividade total dos fatores e a pobreza no Brasil como um todo. Este estudo tem como base os trabalhos de Fan e Chan-Kang (2005) e Fan et al. (2002), os quais investigam o papel dos gastos públicos na redução da pobreza na China e na China Rural, respectivamente.

Os principais resultados de Cruz et al. (2010) mostram que maior nível educacional, melhores condições de saúde, acréscimos na formação bruta de capital fixo e melhorias na infraestrutura rodoviária e energética contribuem significativamente para elevar a renda per capita e a produtividade total dos fatores (PTF) nacionais, indicadores de relação inversa com o número nacional de pobres. A pesquisa evidencia que, apesar do desempenho econômico modesto e da pobreza ainda ser um grave problema social, houve crescimento econômico acompanhado de queda na pobreza entre 1980 e 2007. Todavia, a efetividade dos gastos públicos tem relação com a estrutura socioeconômica do espaço de análise, principalmente num país de dimensões continentais, como o Brasil. Os efeitos dos gastos públicos tendem a ser diferentes, consideradas as particularidades de cada região. Nesse contexto, torna-se pertinente avaliara atuação do gasto governamental em capital humano e físico nos estados brasileiros. A ideia é que, para a mesma taxa de crescimento, o impacto na redução da pobreza possa apresentar significativa variância do ponto de vista regional.

Sob esse ponto de vista, o presente artigo propõe tal análise para os estados brasileiros, seguindo o modelo proposto em Cruz et al. (2010). Assim, torna-se 
possível avaliar de que forma os gastos públicos em infraestrutura e em capital humano podem ser alocados de maneira eficaz para atingir ambas as metas: crescimento econômico e queda de pobreza nos estados brasileiros de 1995 a 2008. O que se espera é que a possibilidade de expansão dos estoques de infraestrutura e de capital humano possa contribuir para melhores oportunidades socioeconômicas para os pobres e melhor distribuição de renda, via aumento dos retornos dos insumos capital e trabalho. Entre as justificativas para essa análise incluem-se as pressões orçamentárias que o Estado e as unidades federativas enfrentam, além das reduzidas margens para expansão das receitas fiscais.

No que se refere à estrutura, além da introdução e das considerações finais, o presente trabalho contém a segunda seção, que relata os principais estudos teóricos e empíricos dentro da temática investigada, de modo a dar suporte aos resultados encontrados. Na terceira seção, apresenta-se a metodologia, com detalhamento do sistema de equações proposto e sua fonte de dados. Por fim, são discutidos os resultados obtidos à luz da teoria e da conjuntura econômica do período analisado.

\section{Aspectos da Literatura sobre Políticas Públicas de Crescimento}

No século XX, mais especificamente após a Segunda Guerra Mundial, com a concretização do chamado Estado de Bem-Estar, inicia-se a defesa da importância dos gastos públicos, dando impulso ao debate sobre a formulação de políticas eficazes voltadas para a questão social mundial. Sobre o aspecto social, ao longo de sua trajetória, o Brasil desenvolveu características marcantes, entre as quais se destacam a desigualdade social e a pobreza, que se mostram bastante estáveis, indicando que o problema não é circunstancial, mas sim, estrutural.

O termo desigualdade social, bastante recorrente, tem sua definição envolvida por diversos tipos de desigualdade (de educação, de oportunidades, de renda, entre outros). Em síntese, a desigualdade econômica entre os indivíduos de uma nação denomina-se de desigualdade social, levando-se em consideração a distribuição da renda. Isso porque o aumento de renda não proporciona a inserção social diretamente, uma vez que depende de variáveis multidimensionais. Dessa forma, políticas que visam apenas ao aumento da renda média como instrumento de redução da desigualdade tendem a ser apenas políticas de curto prazo, com efeitos limitados sobre outras áreas.

Nesse contexto, emerge a importância das políticas públicas pautadas na possibilidade de conceder à população acesso aos serviços de educação, saúde, inclusão digital, participação política, entre outros bens sociais. Assim, o simples aumento de renda, enquanto condição necessária, não é suficiente para a obtenção desses serviços. Para Sen (1983), não é condição suficiente aumentar os recur- 
sos financeiros do indivíduo, mas é sumariamente importante ampliar suas oportunidades de escolhas, no intuito de elevar o nível do bem-estar. Isso é possível por meio do investimento em capital humano, o que viabiliza agregação de conhecimento e, com isso, eleva a renda, permite acesso à saúde e possibilita maior participação nas decisões políticas do país, ou seja, expande as oportunidades do indivíduo enquanto cidadão.

No centro dessas questões, destaca-se o conceito de crescimento pró-pobre, que faz com que o aumento generalizado da renda beneficie o pobre proporcionalmente mais que ao não pobre. Esse tipo de dinamismo econômico faz referência à inclusão dos pobres na geração do crescimento econômico e usufruto de seus resultados.Não obstante, a literatura sobre o crescimento pró-pobre é ampla e diversificada. Os trabalhos de White e Anderson (2000) e de Manso, Barreto e França (2009) limitam a discussão dessa definição em torno da relevância de dois indicadores para a redução da pobreza: desigualdade de renda e crescimento da renda média.

Defendendo a visão que leva em consideração a desigualdade de renda, Lopez (2004) mostra que crescimento "pró-pobre" se dá quando a participação da renda dos mais pobres da população aumenta mais que proporcionalmente ao crescimento da renda média da economia, culminando na queda da desigualdade lado a lado com o crescimento dos rendimentos. Nessa linha de pensamento, White e Anderson (2000) defendem o critério da variação positiva da renda dos pobres, pelo menos tanto quanto a mudança da participação desta camada na população. Em outras palavras, há aumento da renda per capita dos mais pobres e, por conseguinte, a queda da desigualdade absoluta. No entanto, como estudiosos defensores do crescimento da renda, Ravallion e Chen (2003) usam como justificativa sua capacidade de reduzir a pobreza para determinada medida pré-estabelecida, independente do ocorrido com o nível de desigualdade. Já Kakwani e Pernia (2000) mesclam ambos os indicadores e sugerem a comparação entre as mudanças na pobreza devido ao crescimento econômico e aquelas devidas às alterações reais na desigualdade.

O fato é que nenhuma dessas definições está isenta de contradições, dada a complexidade do tema. Em meio à discussão sobre o crescimento pró-pobre dever-se-ia aprofundar no foco do problema, a pobreza, para depois caracterizá-la. A noção de pobreza refere-se a algum tipo de privação (material ou de elementos culturais e sociais), ou mesmo de natureza absoluta, relativa ou subjetiva. Hagenaars e De Vos (1988) classificam a pobreza em três categorias: a pobreza absoluta, caracterizada pela detenção de nível de renda inferior ao necessário para consumir os bens considerados essenciais para a vida das pessoas; a pobreza relativa, situação em que o indivíduo possui renda muito abaixo da renda média 
do país; e ainda a pobreza subjetiva, condição na qual o cidadão sente que não detém ganho suficiente para seguir adiante.

Bradshaw e Finch (2003) defendem a privação de bens e condições de vida como o indicador direto de pobreza, sendo a renda apenas um indicador indireto. Já Rocha (1995) enfatiza que a maioria das necessidades no campo do consumo privado é atendida pelas operações de mercado - logo, o nível de bem-estar está estritamente ligado ao nível da renda, ou seja, uma medida de pobreza unidimensional.

Na busca de soluções para a questão da pobreza, a análise das políticas públicas adotadas é essencial. Avaliando-se os gastos públicos que alteram a relação entre os fatores de produção e, desse modo, a dinâmica do mercado de trabalho, pode-se destacar os gastos em capital humano e capital físico. Na discussão do gasto em capital humano e sua relação com o crescimento econômico, Ferreira et al. (2003), supondo rendimentos decrescentes de capital físico e trabalho, explicam o crescimento de longo prazo pelo avanço tecnológico, que eleva a produtividade dos fatores de produção. No caso de Blackburn, Hung e Pozzolo (2000), o estudo comprova que a acumulação de capital humano é fator determinante para o progresso tecnológico. No que diz respeito à assimilação de novas tecnologias, segundo Foster e Rosenzweig (1996), pessoas mais educadas são mais capazes de assimilar novas informações e de gerir novas tecnologias, tirando maiores proveitos de mudanças tecnológicas. Sob tal lógica, o processo de crescimento cada vez mais embasado em tecnologia, inovação, e conhecimento resulta em melhor condição de vida daqueles de nível educacional superior. Todavia, dada a relativa menor capacidade de acesso à educação de boa qualidade pelos mais pobres, identifica-se, na ausência de investimento em capital humano o cenário de baixa produtividade e renda destes indivíduos colocados à margem da sociedade.

Insere-se aqui a importância, portanto, de se discutir também a literatura teórico-empírica sobre a capacidade dos investimentos públicos em capital humano de complementar os gastos individuais daqueles afetados pelas imperfeições dos mercados. O gasto em capital humano tem a particularidade de permitir que o indivíduo consiga reduzir seu nível de pobreza, por intermédio do próprio esforço, sendo assim uma política sustentável de combate à pobreza e promoção do crescimento econômico, via aumento da produtividade.

Segundo Lopez (2013), sob o ponto de vista do impacto da infraestrutura na distribuição de renda, se o investimento em infraestrutura é um instrumento de política em áreas pobres e tais áreas administram as novas oportunidades, a infraestrutura pode também reduzir a desigualdade. Esse tipo de investimento público produtivo pode ainda, potencialmente, aliviar a desigualdade, mesmo se uniformemente distribuído. Este seria o caso em que os grupos mais pobres da sociedade enfrentariam restrições de crédito, impedindo-os de adquirir substitutos 
privados dos bens de infraestrutura. Estando a classe mais rica hábil para complementar a provisão pública desses serviços, formam-se, então, as chamadas parcerias público-privadas.

Desse modo, os formuladores de políticas, cuja meta seja a redução da pobreza, devem definir os níveis eficazes de gastos em capital humano e capital físico, considerando que há relação entre esses dois gastos e a possibilidade de crescimento do tipo pró-pobre. Nessa análise, é necessário também levar em consideração as condições da economia, para que seja possível o melhor aproveitamento dos recursos públicos frente suas metas de desenvolvimento econômico.

A seguir, testa-se empiricamente a importância dos gastos públicos em capital físico e humano para promover o crescimento econômico e, ao mesmo tempo, reduzir a pobreza nos estados brasileiros.

\section{Metodologia}

Seguindo o método proposto em Cruz et al. (2010), na identificação da importância dos gastos públicos em capital físico e humano para promover o crescimento econômico pró-pobre, parte-se do pressuposto da inter-relação entre as variáveis econômicas abordadas.Isso significa dizer que determinada variável pode não apenas exercer, mas também sofrer influência de outras variáveis. Nesse sentido, torna-se viável o uso de um modelo de equações simultâneas, que permite interações diretas e indiretas entre variáveis endógenas e exógenas, considerando como essenciais todas as relações presentes no sistema. Nessa abordagem, as variáveis endógenas são geradas mútua e simultaneamente, enquanto as exógenas são determinadas fora do sistema.

A seguir, detalha-se o sistema de equações base do estudo. Os sinais (positivo ou negativo) entre parênteses apontam as relações esperadas entre as variáveis explicativas e as explicadas.

$$
\begin{aligned}
& E d u c_{t}=\psi_{0}+\psi_{1} \text { Geduc }_{t}+\psi_{2} \text { Geduc }_{-1 t}+\ldots . .+\psi_{j} G e d u c_{-i t}+\varsigma_{t} \\
& (+) . \quad(+) \quad \ldots \ldots \ldots \ldots \ldots \ldots \ldots . . .(+) \\
& \operatorname{Sau}_{t}=\rho_{0}+\rho_{1} \operatorname{Gsau}_{t}+\rho_{2} \operatorname{Gsau}_{-1 t}+\ldots . .+\rho_{j} \operatorname{Gsau}_{-t}+\psi_{t} \\
& (-) \quad(-) \ldots \ldots \ldots \ldots \ldots \ldots \ldots . . .(-) \\
& \operatorname{Rod}_{t}=\eta_{0}+\eta_{1} \operatorname{Grod}_{t}+\eta_{2} \operatorname{Grod}_{-1 t}+\ldots . .+\eta_{j} \operatorname{Grod}_{-t}+\tau_{t} \\
& (+) \ldots \ldots \ldots \ldots \ldots \ldots . . .(+) \\
& \text { Emp }_{t}=\varphi_{0}+\varphi_{1} \text { Geduc }_{t}+\varphi_{2} \text { Grod }_{t}+\varphi_{3} \text { Gsau }_{t}+\varphi_{4} \operatorname{sal}_{t}+\gamma_{t} \\
& \text { (+) (+) (+) (-) }
\end{aligned}
$$




$$
\begin{gathered}
\mathrm{Sal}_{t}=\phi_{0}+\phi_{1} \operatorname{cresc}_{t}+\phi_{2} \mathrm{emp}_{\mathrm{t}}+\phi_{3} \text { Pemp }_{t}+\phi_{3} \operatorname{cam}_{t}+\delta_{t} \\
(-) \quad(-) \quad(+) \quad(-) \\
P I B_{t}=\alpha_{0}+\alpha_{1} e d u c_{t}+\alpha_{2} \operatorname{Sau}_{t}+\alpha_{3} \operatorname{rod}_{t}+\alpha_{4} \text { Pemp }_{t}+\varepsilon_{t} \\
(+) \quad(+) \quad(+) \\
\text { Pob }_{t}=\omega_{0}+\omega_{1} \text { Pemp }_{t}+\omega_{2} \text { PIB }_{t}+\omega_{3} \text { pop }_{t}+\omega_{4} \text { conc }_{t}+\varphi_{t} \\
(-)
\end{gathered}
$$

As equações de 1 a 3 relacionam as condições de educação (educ), saúde (sau) e das rodovias (rod) aos gastos correntes e passados em educação, em saúde e em transporte rodoviário, respectivamente. O objetivo é avaliar a efetividade dos gastos públicos quanto à melhoria das condições de infraestrutura física e do estoque de capital humano, consideradas as estruturas de cada estado.

Dados os efeitos diretos e indiretos dos estoques de capital físico e humano sobre os salários da economia, espera-se também que este efeito se traduza em elevação do número de trabalhadores no mercado de trabalho. Afinal, esses tipos de gastos públicos tendem a estimular o crescimento da economia e, assim, dinamizam as atividades econômicas. Desse modo, na equação 4, espera-se que o emprego em cada estado reflita efeitos positivos advindos de gastos do governo em capital humano - educação (Geduc) e saúde (Gsau) - e em infraestrutura física das estradas (Grod). Já a presença da variável de salários (sal) está ligada à demanda de trabalho, cuja hipótese é de relação negativa com a parcela da População Economicamente Ativa (PEA) de indivíduos ocupados no estado.

$\mathrm{Na}$ equação 5, avalia-se o comportamento dos salários sob a ótica da demanda de trabalho, segundo a abordagem neoclássica da Economia do Trabalho. Espera-se que o salário real tenha relação positiva com a produtividade do emprego, Рemp, mas apresente relação contrária com a parcela da PEA efetivamente empregada (emp). Afinal, segundo a teoria da demanda de trabalho, o emprego assume, por hipótese, relação inversa com o salário. Na expectativa de relação inversa entre crescimento populacional (pop) e salário real, toma-se por base o cenário em que o crescimento populacional excessivo pode culminar em excesso de oferta de trabalho, mediante o crescimento em ritmo mais acelerado da PEA que o aumento da população ocupada.

No caso da justificativa da inclusão da taxa de câmbio real (cam), esta se fundamenta na sua relação com a participação dos salários e dos lucros na renda estadual. Quanto mais apreciado o câmbio, menores as exportações e maiores as importações, e maior a tendência ao déficit em conta corrente (poupança externa). Nesse contexto, a apreciação cambial pode elevar, em termos reais, os salá- 
rios dos trabalhadores e os ordenados da classe média profissional, mas reduzir os lucros dos capitalistas, os quais exportarão e investirão menos. A razão é que os preços dos bens de consumo comercializáveis internacionalmente (commodities) diminuem com a apreciação da moeda local. A variação nos salários com relação ao câmbio será tanto maior para cada família, quanto maior o consumo de bens comercializáveis, e maior a sensibilidade das exportações e importações à taxa de câmbio (BRESSER-PEREIRA; GALA, 2008).

Já na equação (6), o PIB per capita é relacionado à quilometragem de rodovias pavimentadas no estado, variável de infraestrutura física, às medidas de capital humano, educação e saúde, e à produtividade do emprego. Quanto aos sinais dos coeficientes, com exceção da taxa de mortalidade, são esperados impactos positivos sobre o crescimento da renda per capita dos estados. Essa expectativa tem por base a premissa de que boas condições de educação e de saúde, alta produtividade do trabalho e viabilidade na infraestrutura rodoviária tendem a influenciar positivamente o processo de produção, contribuindo para a criação e absorção de novas tecnologias, com consequente acréscimo da renda per capita estadual.

Por fim, na equação (7), a variável dependente é o número de pobres nos estados. A inclusão da variável PIB per capita como explicativa tem por objetivo verificar se, no período analisado, o crescimento econômico foi suficiente para reduzir a pobreza estadual, ou seja, se há evidência de crescimento pró-pobre nas federações. A equação inclui também a variável produtividade do trabalho (Pemp), cuja relação com a intensidade de pobreza espera-se que seja inversa, por meio de sua atuação positiva no mercado de trabalho. Já a variável concentração de renda (conc), medida pelo índice de Gini, é incluída, diante da suposição de que a desigualdade na distribuição de renda eleve a pobreza. Acredita-se que o maior crescimento populacional agrave as condições de vida da população, no contexto de infraestrutura física e social insuficientes para atender ao excedente populacional, elevando, portanto, o total de pessoas pobres na sociedade.

No que diz respeito ao instrumental analítico para estimar os efeitos públicos no universo da estrutura socioeconômica dos 27 estados brasileiros, usou-se da estrutura de dados em painel, no período 1995-2008. ${ }^{1}$ Trata-se de um painel equilibrado, uma vez que cada unidade de corte transversal $(\mathrm{N})$ possui o mesmo número de séries temporais $(\mathrm{T})$. Cabe dizer que, entre as principais vantagens do uso de dados em painel, Gujarati (2006) enumera que o método considera explicitamente a heterogeneidade entre as unidades estudadas, proporciona dados mais informativos, com mais graus de liberdade e maior eficiência e minimiza o viés decorrente da agregação de unidades em grandes conjuntos.

Dito isso, duas abordagens foram testadas: o modelo de efeito fixo e o modelo de efeito aleatório. A proposta é separar os fatores não observados que afetam

1 O período não se estende até a atualidade, em razão da limitação de dados estaduais atualizados. 
a variável dependente em dois tipos: os que são constantes (efeito fixo) e os que variam ao longo do tempo (efeito aleatório). O primeiro caso leva em consideração os efeitos específicos atrelados às unidades individuais, no caso os estados, principalmente quando existe grande heterogeneidade na amostra. Nesse sentido, o modelo geral da regressão a estimar segue a seguinte expressão:

$$
Y_{i t}=\beta X_{i t}+v_{i t}
$$

com $v_{i t}=\alpha_{i}+u_{i t}$ e com $\mathrm{i}=1, \ldots, \mathrm{N}$ e $\mathrm{t}=1, \ldots, \mathrm{T}$, em que $Y_{i t}$ representa a variável dependente do estado i no ano t; $X_{i t}$ representa as variáveis explicativas de Y do estado i no ano t; $\beta$ corresponde aos parâmetros da regressão a estimar; $\alpha_{i}$ corresponde aos fatores específicos dos estados, de forma que $\alpha_{i} \approx\left(0, \sigma_{\alpha}^{2}\right)$, que não são diretamente observáveis pelos determinantes de Y e $u_{i t}$ é o termo da perturbação aleatória do estado $i$ no ano $t$, tal que $u_{i t} \approx\left(0, \sigma_{u}^{2}\right)$. Temos ainda que $\mathrm{E}\left(u_{i t} \alpha_{i t}\right)=0$ e $\mathrm{E}\left(u_{i t} X_{i t}\right)=0$.

Se $\alpha_{i}$ for constante, obtém-se o modelo com efeito fixo. A variável $\alpha_{i}$ capta todos os fatores não observados constantes no tempo e que afetam Y. Por outro lado, se $\alpha_{i}$ for variável, obtém-se o modelo com efeito aleatório. Essencialmente, o que diferencia o modelo de efeitos aleatórios do de efeitos fixos seria a hipótese de não correlação entre o efeito não observado $\alpha_{i}$ e as variáveis explicativas. A existência de correlação entre o efeito individual e os regressores pode ser detectada por meio da aplicação do teste de Breusch-Pagan (GREENE, 2002), que identifica se o modelo de efeito aleatório é melhor que o modelo pooling. Já o teste de especificação de Hausman (1978) segue a hipótese nula de que não há correlação entre $\alpha_{i}$ e $X_{i t}$, seguindo a estatística de teste Qui- Quadrado. No caso de haver correlação, a estimação deve ser feita a partir do estimador de efeito fixo. Caso contrário, o estimador de efeito aleatório é o mais apropriado.

Para atestar a inexistência de autocorrelação serial dos erros idiossincráticos, faz-se o proposto em Wooldridge (2002), cuja hipótese nula é de ausência de correlação entre os termos de erro, $\mathrm{E}\left(\varepsilon_{\mathrm{is}}, \varepsilon_{\mathrm{it}}\right)=0$ para todo $\mathrm{s} \neq \mathrm{t}$, a partir de uma distribuição F. Seguindo o Guan (2003), o teste usa uma regressão em primeira diferença para obter os resíduos estimados, $\hat{\varepsilon}_{\mathrm{it}}$. O próximo passo é a estimação da regressão desses resíduos em função das variáveis explicativas e de defasagens (lags). Se os erros não são serialmente correlacionados, tem-se $\operatorname{Corr}\left(\Delta \varepsilon_{t}, \Delta \varepsilon_{t-1}\right)=-0,5$.

Outro problema que compromete os estimadores obtidos é a heterocedasticidade dos grupos nos painéis. Para tal, atentou-se à realização do teste baseado na distribuição $\chi^{2}$ (Quadrado) para dados de painéis proposto por Greene (2002). Nesse método, é possível verificar se os grupos apresentam variâncias idênticas ou não entre os painéis (group wise heterokesdasticity test). 


\subsection{Método dos Mínimos Quadrados Generalizados com Variáveis Instrumentais}

Diante da endogeneidade de algumas variáveis, cuja estimação pelo método de Mínimos Quadrados Ordinários MQO tende a revelar estimadores não consistentes. Dessa forma, buscou-se identificar o melhor método para eliminar o possível viés advindo da correlação supracitada. Entre os modelos, consta o Método dos Mínimos Quadrados de Dois Estágios com Variáveis Instrumentais, aplicado ao modelo de efeito fixo e ao modelo de efeito variável. Nesse caso, os estimadores obtidos são consistentes e possuem distribuição assintótica normal, desde que os instrumentos usados sejam validados: sejam exógenos e correlacionados com a variável explicativa. Todavia, este estudo seguiu o recomendado na literatura que trata da estimação de equações com variáveis instrumentais, a partir de um curto recorte temporal, qual seja: o Método dos Momentos Generalizados (GMM) proposto por Hansen (1982).

O estimador GMM pertence à classe conhecida de estimadores que minimizam a função-objetivo, sendo robusto, pois, assintoticamente, não requer a informação da distribuição exata das perturbações (QMS, 2004). A estimação GMM supõe que as perturbações nas equações não são relacionadas ao conjunto de variáveis instrumentais, ocorrendo seleção das estimativas dos parâmetros, de forma que as correlações entre os instrumentos e os erros sejam próximas de zero o quanto possível. Entre as vantagens do método tem-se que: a) não demanda suposição da distribuição, tal como a normalidade dos erros; b) permite heterocedasticidade de forma desconhecida; e c) calcula parâmetros, mesmo sob a condição de não solução analítica nas condições de primeira ordem. Cabe informar que, a partir do uso do GMM com variáveis instrumentais, os estimadores são consistentes, sob a suposição de homocedasticidade e não correlação serial dos erros. Feita a escolha por este instrumental, é primordial testar a validade dos instrumentos, bem como a identificação das equações estimadas no sistema, cujas conclusões são descritas na seção de resultados.

No que se refere aos dados, trabalhou-se com informações anuais referentes aos 27 estados brasileiros, no período de $1995-2008 .^{2}$ A seguir, são descritas as variáveis e suas respectivas fontes:

- Variáveis endógenas

PIB per capita (mil reais a preços de 2008); Salário real - rendimento médio nominal do trabalho principal (mão de obra ocupada na região metropolitana) deflacionado com base no Índice Geral de Preços (IGP-DI) do IBGE; Número (milhões) de pessoas abaixo da linha de pobreza; Educa-

2 Em alguns casos, usou-se do método de interpolação e de extrapolação para dados de algumas variáveis não disponibilizados nos anos 2000 e 2008. 
ção - Anos médios de escolaridade da parcela da população com 25 anos ou mais; Saúde - taxa de mortalidade infantil (em \%); Nível de emprego - razão entre a população ocupada (PO) e a população economicamente ativa (PEA) (ver IPEADATA, 2012);

Rodovias - total em quilômetros de rodovias federais e estaduais pavimentadas (ver Anuários Estatísticos dos Transportes Terrestres disponibilizados pela Agência Nacional de Transportes Terrestres, conforme período de análise).

\section{- Variáveis exógenas}

Índice de concentração de Gini. Taxa de câmbio efetiva real - INPC - exportações de manufaturados em número índice; Produtividade do emprego - razão entre o valor adicionado e a população ocupada, seguindo o Ipeadata (2012); ${ }^{3}$

Crescimento populacional - taxa média geométrica de crescimento da população (IBGE, 2009);

Gastos públicos estaduais e federais em educação e cultura, em saúde e saneamento e em transporte rodoviário- Execuções Orçamentárias da União e dos Estados (valores em reais atualizados com base no IGP-DI) (ver BRASIL, 2013).

\section{Análise e Discussão dos Resultados}

Nesta seção, são apresentados os resultados do sistema de equações proposto a partir do Método dos Momentos Generalizados (Generalized Moments Method - GMM). Foram testadas as especificações pelo Método dos Mínimos Quadrados de Dois Estágios. Todavia, o sistema obtido por GMM apresentou-se com melhor ajuste no que se refere à significância estatística dos parâmetros e do ponto de vista das relações teóricas previstas ou mesmo na validade das variáveis instrumentais usadas e na qualidade do ajustamento do modelo. É importante mencionar que, quando identificados problemas de variância não constante dos erros e autocorrelação serial nos painéis obtidos, por meio dos testes de Wooldridge e de Wald modificado, procedeu-se à correção destas violações, a partir de vetores de correção de erro adequados ao GMM.No que concerne à escolha do modelo de efeito fixo ou de efeito variável, na aplicação do teste de Hausman, com exceção de duas equações, cujos resultados foram inconclusivos, todas as demais apontam a forma de efeito fixo como mais eficiente. Na Tabela 2, são apresentados os resultados do sistema estimado por GMM.

3 As estimativas de produtividade total dos fatores não se apresentaram viáveis, principalmente em razão de muitos indicadores necessários e não disponíveis para os estados brasileiros, segundo o recorte de tempo desta pesquisa. 


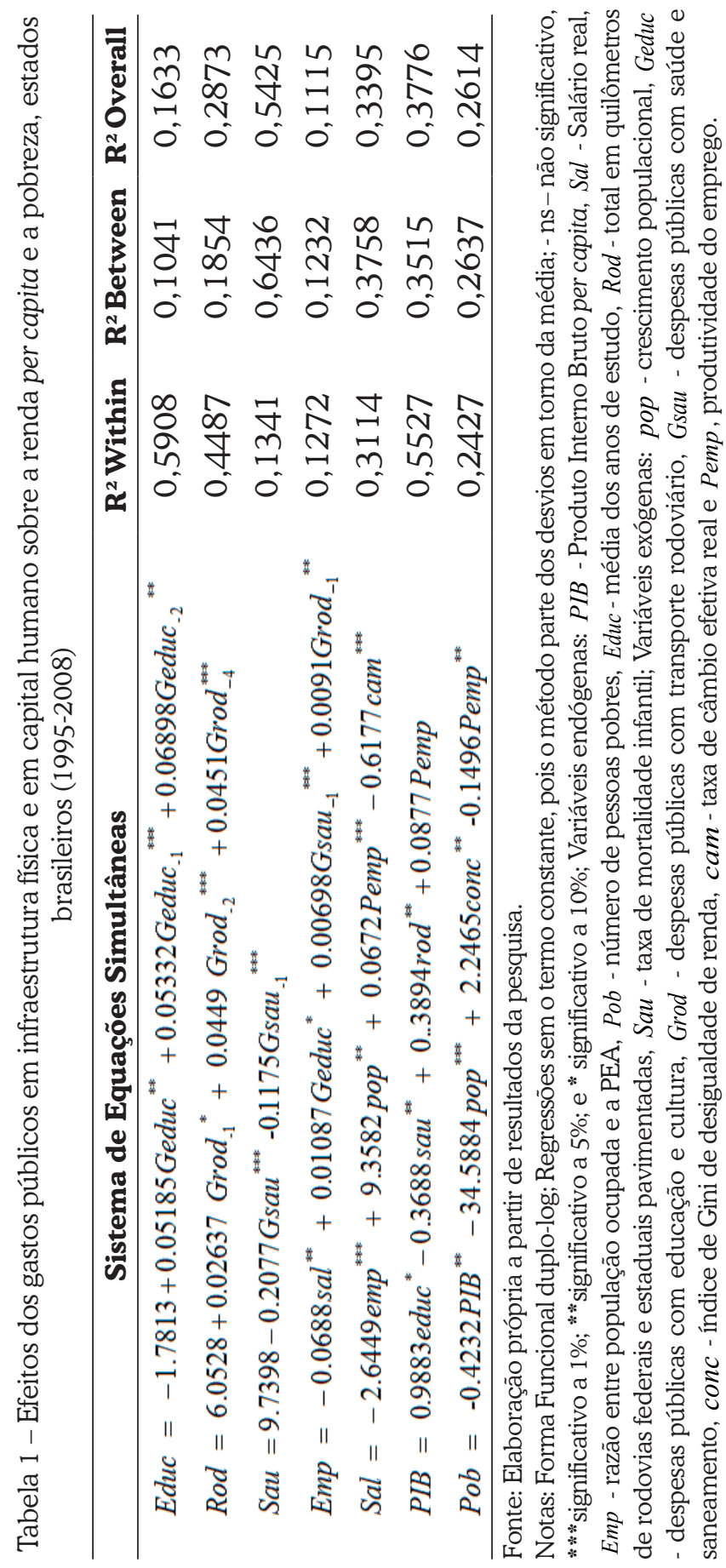

CRUZ, A. C.; TORRES, D. A. R.; TEIXEIRA, E. C. Gastos Públicos em Infraestrutura e em... 
Primeiramente, é importante atentar para o fato de que os coeficientes de ajustamento para cada equação são relativamente próximos entre si, mostrando que as variáveis explicativas incluídas na equação têm peso explicativo semelhante nas mudanças das variáveis dependentes, seja entre ou intraestados. Os maiores níveis de ajustamento se devem às equações que atestam que os gastos públicos estaduais são efetivos quanto ao aumento do estoque de capital humano (saúde e educação) e de melhoria da infraestrutura rodoviária.

No que se refere às especificidades de cada regressão, as primeiras três equações têm por objetivo fazer inferências sobre a eficácia dos gastos públicos analisados. Os resultados revelam que as despesas dos governos federal e estadual nos estados brasileiros em educação, saúde e em transporte rodoviário permitem melhorias no nível de escolaridade, redução da taxa de mortalidade infantil e avanços na infraestrutura rodoviária estadual, respectivamente.

A primeira equação mostra que os gastos estaduais em educação e cultura conseguem explicar 59\% das variações do número de anos de estudo da população, na análise intraestadual. Percebe-se ainda que os efeitos dos dispêndios do governo não se esgotam em um período, pois os gastos correntes e os gastos públicos com duas defasagens mostram-se estatisticamente significativos com relação direta com os acréscimos na escolaridade em cada estado brasileiro. Apesar do baixo valor dos coeficientes de elasticidades, dada a forma funcional duplo logaritmizada, os efeitos não se reduzem com o passar do período em que os recursos financeiros foram canalizados para a educação. Especificamente, em média, espera-se que o aumento de $10 \%$ do volume financeiro direcionado para a educação promova aumento de $0,58 \%$ na escolaridade média estadual.

Avaliando a evolução da educação do brasileiro, tem-se que a taxa de frequência escolar ao ensino fundamental de 2008 era de 97,9\% (IBGE, 2008), o que mostra avanço na comparação com 1998 (94,7\%), embora a taxa de conclusão seja bem inferior e pouco acima dos 40\%. Vale lembrar que, durante os anos 2000, muito desse quadro se deve às condicionalidades dos programas de transferência de renda, Entretanto, segundo Rigotto e Souza (2005), dos concluintes do ensino básico, apenas 72,2\% seguem para o ensino médio, enquanto o restante fica à margem do mercado de trabalho, com baixa instrução e preparo insuficiente para o mercado de trabalho. Os autores alertam ainda para a importante questão da distorção entre idade e ano escolar, um obstáculo ao ensino secundário em virtude do atraso na conclusão do ensino fundamental.

Nesse cenário, uma forma de identificar a eficácia do sistema educacional nacional e de vislumbrar a capacidade da sociedade de combater a pobreza e melhorar a coesão social é avaliar a representatividade da população jovem de 18 a 24 anos de idade que tem 11 anos de estudo. No Brasil, segundo dados da PNAD de 2008, o percentual de jovens que possuem essa escolaridade ainda é extrema- 
mente baixo (36,8\%), embora este percentual tenha dobrado em relação a 1998 (18,1\%). No comparativo inter-regional, as desigualdades regionais são marcantes, visto que no Sudeste a faixa etária de 18 a 24 anos com 11 anos de estudo, em 2008 , era de $43,8 \%$, enquanto no Nordeste, apenas $29,2 \%$ dos jovens nesta faixa etária possui tal nível de instrução.

De fato, as melhorias no quadro educacional brasileiro são na sua maioria quantitativas. Segundo dados do Ipeadata (2012), 2,21\% da população brasileira de 15 a 24 anos de idade não sabe ao menos escrever um simples bilhete, sendo que, em treze estados brasileiros, este percentual é maior. Os destaques são para os estados de Maranhão e Alagoas, cuja parcela dessa faixa etária de analfabetos é de 5,95\% e 8,37\%, respectivamente. Na outra ponta, aparece o Distrito Federal com $0,63 \%$ e o Amapá, com apenas 0,23\%. Atenta-se ainda para o analfabeto funcional, cuja representatividade em 2008 atinge os $21 \%$ da população brasileira com 15 anos ou mais. Esses indivíduos não conseguem interpretar um texto, sendo que no meio rural essa percentagem eleva-se para 41,8\%. Conforme o esperado, os estados do Norte e Nordeste destacam-se com percentuais de analfabetos funcionais na ordem de $24,2 \%$ e $31,6 \%$, respectivamente, no mesmo ano. Surge, dessa forma, outro entrave na busca do aumento do estoque de capital humano, tendo em vista a superioridade da qualidade do ensino superior público em relação ao privado, em razão do processo de seleção mais criterioso, entre outros fatores. Contudo, apesar dos traços negativos do Norte e Nordeste, há um mérito a se destacar. No comparativo, são as regiões com maior parcela da população frequentando o ensino superior público: 36,7 e 34,1\%, respectivamente. Se consideradas as instituições privadas, esse número atinge 63,3\% e 65,9\%. No Norte, os destaques são os estados do Amazonas e Roraima, enquanto no Nordeste despontam a Paraíba e o Piauí. ${ }^{4}$ Embora os avanços quantitativos no sistema educacional sejam uma realidade, há ainda muito que se planejar e executar frente ao objetivo de elevar a qualidade do estoque de capital humano dos estados, consideradas suas particularidades, de forma a reverter o cenário de pobreza ainda preocupante.

Na segunda equação do sistema, comprova-se que os gastos em saúde permitem avanços nas condições de saúde da população. A significância estatística dos coeficientes negativos que testam a relação entre gastos estaduais nesta categoria e as taxas de mortalidade estadual, segundo o recorte temporal do trabalho, corroboram este resultado. As despesas estaduais em saúde explicam $44,87 \%$ das quedas na mortalidade infantil intraestadual e $18,54 \%$ das alterações na variável de saúde entre os estados brasileiros. Diante da significância estatística das defasagens desses gastos, pode-se dizer que os dispêndios públicos correntes e passados em saúde são capazes de promover redução da mortalidade. De maneira comparativa, os efeitos dos gastos estaduais em saúde são consideravelmente superiores

$4 \quad$ Para mais detalhes ver IBGE (2009).

CRUZ, A. C.; TORRES, D. A. R.; TEIXEIRA, E. C. Gastos Públicos em Infraestrutura e em... 
aos gastos em educação, considerando-se as elasticidades. Denota-se que a possibilidade de aumento de $10 \%$ nesse tipo de gasto público tende a reduzir a taxa de mortalidade em $2 \%$ para os gastos correntes. Com a defasagem de um período, esse mesmo percentual de aumento do dispêndio em saúde reduziria em 1,17\% a taxa de mortalidade nos estados.

É importante destacar que a redução dos níveis de mortalidade lado a lado com a evolução da esperança de vida vem corroborar esse indicativo de eficácia dos governos neste setor. $\mathrm{O}$ indicador de esperança média de vida ao nascer para o Brasil, em 2008, estava em 73 anos, resultado do aumento da vida média ao nascer, entre 1998 e 2008, em torno de 3,3 anos. Na análise entre estados, a divergência entre os valores da esperança de vida do Distrito Federal e de Alagoas em 1998 era de 9,7 anos. Uma década depois, essa discrepância cai para 8,4 anos. Já a taxa bruta de mortalidade decresceu de 6,53\% para 6,22 \% no mesmo período. Pode-se inferir, pois, que as melhorias nas condições de habitação, em termos de saneamento básico adequado e maior cobertura dos serviços de saúde, certamente têm atuado para reduzir a mortalidade infantil.

A verdade é que poder afirmar que as despesas estaduais em saúde e saneamento são efetivas quanto à redução da taxa de mortalidade infantil no Brasil é um resultado muito positivo. Embora a taxa de mortalidade infantil revele tendência decrescente, ainda é elevada em relação às nações vizinhas. $\mathrm{O}$ cotidiano do brasileiro ainda é marcado por dificuldades de acesso a condições dignas de tratamento de saúde, entre outras políticas correlatas. Nessa discussão, é essencial atentar-se para a complementaridade entre saúde e educação. Anos adicionais de estudo da população feminina, os quais se refletem nos demais membros da família, somados à elevação da parcela populacional com saneamento básico adequado e ao maior acesso aos serviços de saúde contribuem para o arrefecimento da taxa de mortalidade infantil no país. Contudo, há espaço para progressos maiores na área da saúde, buscando, sobretudo, o aumento da expectativa e da qualidade de vida do brasileiro.

Na discussão sobre o impacto das despesas em transporte rodoviário sobre a infraestrutura rodoviária, considera-se a terceira equação do sistema, que investiga a relação entre gastos dos governos federais e estaduais em rodovias considerando-se uma, duas e quatro defasagens. De posse dos valores dos coeficientes das elasticidades, percebe-se que, assim como nas despesas em educação, os efeitos são maiores para os gastos com maior defasagem. Em média, no cenário de acréscimo de $10 \%$ nesse tipo de despesa pública, a possibilidade é de apenas 0,4\% de aumento da quilometragem de rodovias estaduais pavimentadas. Tal resultado condiz com a realidade brasileira de grande gargalo em termos de logística, principalmente embasado nas condições precárias das estradas de todo o país. Tal entrave econômico tem levado à crescente concessão de rodovias para empresas 
privadas como forma de suprir as deficiências do setor de transporte ligadas à baixa eficácia dos gastos públicos nesse capital fixo.

Segundo informações da Pesquisa CNT de Rodovias 2012, realizada pela Confederação Nacional do Transporte (2012), as rodovias são o principal meio de transporte do brasileiro, sendo responsáveis por $61,8 \%$ de toda a carga movimentada e de $96,2 \%$ da locomoção de passageiros pelo país. A pesquisa avalia 95.707 quilômetros de rodovias ao longo do território brasileiro, sendo 80.315 quilômetros de responsabilidade da máquina pública, e informa que 54\% das rodovias pavimentadas nacionais estão com pavimentos em condições satisfatórias, mas $46 \%$ ainda estão em estado deficiente. Se o critério é a sinalização, os números mudam para $33,7 \%$ e $66,3 \%$, respectivamente.

$\mathrm{Na}$ classificação das condições das rodovias, no ranking por percentual das rodovias em ótimo estado de conservação, ocupam os primeiros lugares São Paulo (49,9\%), Rio de Janeiro (20,6\%) e Paraná (18\%). Já o primeiro posto no ranking a partir da maior parcela das estradas em péssimo estado cabe ao Acre (38\%), seguido de Roraima (25,3\%) e do Espírito Santo (22,9\%). De maneira adversa, conforme apontado pela CNT (2012), as despesas operacionais dos veículos tendem a se elevar em $23 \%$, devido às péssimas condições das estradas brasileiras, além da redução da competitividade dos produtos brasileiros com o maior custo de transporte. Aponta-se também os gastos com indenizações de vítimas de acidentes com veículos e o impacto sobre o meio ambiente ligado ao maior gasto com combustível em estradas com estado insatisfatório. Sobretudo, vê-se que a atuação do Governo em suas várias esferas é essencial para dinamizar o setor e permitir que a economia supere os obstáculos impostos por uma infraestrutura de transportes de baixa produtividade e qualidade incipiente. Confirmada a eficácia dos gastos governamentais em relação aos avanços nas suas áreas de enfoque, a quarta equação do sistema investiga os efeitos desses tipos de despesas sobre o estoque de emprego da economia, parcela da PEA que está efetivamente ocupada (Tabela 2). 
Tabela 2 - Efeito dos gastos públicos em infraestrutura física e em capital humano sobre o emprego, estados brasileiros (1995-2008)

\begin{tabular}{|c|c|}
\hline Variável explicativa & Nivel de emprego \\
\hline \multirow{2}{*}{ Gastos públicos em educação e cultura } & $0,01087^{*}$ \\
\hline & $(0,0064)$ \\
\hline \multirow{2}{*}{ Gastos públicos em saúde e saneamento $(-1)$} & $0,00698^{* *}$ \\
\hline & $(0,0036)$ \\
\hline \multirow{2}{*}{ Gastos públicos em transporte rodoviário $(-1)$} & $0,0039 * *$ \\
\hline & $(0,0036)$ \\
\hline \multirow{2}{*}{ Salário real } & $-0,0091 * * *$ \\
\hline & $(0,0026)$ \\
\hline Coeficiente de ajustamento & 0,1272 \\
\hline Teste de subidentificação LM = 58,13 & $P=0,0000$ \\
\hline Teste de Wald de fraca identificação $F=72,99$ & $P=0,0000$ \\
\hline \multicolumn{2}{|l|}{$\begin{array}{l}\text { Teste de superidentificação Sargan: equação exatamente } \\
\text { identificada }\end{array}$} \\
\hline Teste de Wooldrige de autocorrelação $\mathrm{F}=15,76$ & $P=0,0000$ \\
\hline $\begin{array}{l}\text { Teste modificado de Wald de heterocedasticidade chi2 }= \\
102,21\end{array}$ & $\mathrm{P}=0,0000$ \\
\hline Teste de Hausman chi2 $=10,39$ & $P=0,0100$ \\
\hline
\end{tabular}

Fonte: Elaboração própria a partir dos resultados da pesquisa.

Nota: Forma Funcional duplo-log; Valores entre parênteses: erro-padrão; -ns - não significativo, *** "significativo a 1\%, "*significativo a 5\% e *, significativo a 10\%; Instrumentos: ln (cam (-3)).

A regressão estimada possui um coeficiente negativo e estatisticamente significativo para a variável de salários reais, o que é coerente com a teoria que rege a demanda de trabalho na economia. Por outro lado, os gastos em saúde e em energia têm efeitos positivos diretos sobre a razão entre a população ocupada e a PEA (variável de emprego). Cabe destacar que os efeitos diretos positivos dos dispêndios com saúde e dos gastos em rodovias são defasados em um ano.

$\mathrm{Na}$ análise comparativa, a elasticidade emprego dos gastos públicos em educação é superior às elasticidades dos dispêndios em saúde e em transporte rodoviário, valores relativamente baixos e em torno de $0,007 \%$ e $0,009 \%$, respectivamente. Observa-se que, presumindo a ampliação de $1 \%$ nos gastos dos governos voltados à educação, a estimativa é de ampliação em $0,011 \%$ na parcela da PEA de pessoas ocupadas.

No que se refere à relação positiva entre os gastos com saúde e o emprego, pode-se citar uma externalidade positiva para os trabalhadores que saem da con- 
dição de desempregados. Há o impacto sobre a renda familiar e a possibilidade de maior gasto das famílias com serviços de saúde. Dada a complementaridade entre saúde e educação, tem-se associação positiva do maior gasto com saúde e produtividade do trabalho, o que tende a causar um segundo efeito positivo sobre o rendimento dessas famílias, contribuindo para retirar essas pessoas da condição de pobreza. Ou seja, pode-se dizer que recursos direcionados para saúde reduzem o desemprego de forma direta e indireta. Um exemplo é a geração direta e indireta de postos de trabalho ligada à consolidação de programas de saúde, nos quais muitos profissionais são exigidos no processo de criação, implantação e desenvolvimento. Não se pode deixar de mencionar também o Programa Saúde da Família e as equipes de agentes comunitários. Outra forma de geração indireta de demanda por mão de obra está relacionada às atividades industriais e comerciais de produção de medicamentos e insumos hospitalares. Além disso, segundo Biasoto Júnior (2007), diante do aumento do gasto público voltado à atenção básica - promoção e prevenção da saúde - pode-se reduzir a prevalência de especialidades médicas e ampliar a demanda no mercado de trabalho por outros tipos de profissionais da saúde.

Como forma de permitir que toda a população usufrua dos efeitos positivos do crescimento econômico, alerta-se para as políticas públicas que suscitem contratação de força de trabalho. Afinal, esta mão de obra terá sua capacidade de consumo elevada por meio da renda do trabalho, adquirindo bens e serviços, refletindo, por sua vez, o efeito multiplicador dos dispêndios públicos. A proposta é seguir essa máxima sem o agravamento da dívida pública, de modo que os governos federal e estadual possam mudar a composição de seus gastos, com destaque à educação, tal como mostra o presente estudo. Deve ser dada menos ênfase às categorias de gastos que não geram empregos e priorizar a infraestrutura física e social, que permitem a redução do desemprego na economia. Ademais, a redução do desemprego pode vir acompanhada da possibilidade de redução de alguns tipos específicos de gastos, como o pagamento de seguro-desemprego.

Sobre a relação em gastos com infraestrutura e a geração de empregos, segue-se a abordagem keynesiana que destaca a importância do efeito multiplicador e alerta para a questão das obras em infraestrutura demandarem obras a serem executadas pelo setor privado, gerando empregos e produção de insumos. Dessa perspectiva, de acordo com os resultados de Silva et al. (2009), os estados brasileiros não conseguem manter um crescimento econômico sustentado, a menos que a tendência de gastos públicos em transportes seja revertida, aumentando o volume e melhorando a qualidade dos gastos no setor. A análise de dados em painel aqui feita mostra que o "espetáculo do crescimento" somente será realidade mediante o direcionamento de recursos necessários a projetos de gastos em infraestrutura física que atenuem os gargalos comprometedores do investimento, da 
produtividade das empresas e do potencial de crescimento e criação de empregos nos estados brasileiros.

No entanto, é pertinente pontuar que um país de dimensões continentais, cuja faixa etária está em fase de amadurecimento e enfrenta dificuldades nas áreas de educação e formação profissional, tem em frente um grande desafio ligado a sua capacidade de continuar a gerar condições mínimas de absorção da força de trabalho. Segundo Cruz et al. (2010), deve-se atentar para os obstáculos à eficácia dos gastos quanto ao propósito de elevar a parcela de pessoas efetivamente ocupadas, quais sejam: o baixo nível de instrução e qualificação profissional da PEA; o volume ainda insuficiente de recursos direcionados para essas funções de gasto; e o crescimento acelerado da PEA superior ao número de postos de trabalho.

A seguir, são apresentados os resultados que tratam da quinta equação do sistema que discute algumas variáveis chaves para explicar o comportamento dos salários da economia dos estados (Tabela 3). Nessa estimação, buscou-se identificar variáveis que explicam o comportamento dos salários, além do nível de emprego: a taxa de câmbio, a produtividade do emprego e o crescimento populacional, definidas como inter-relacionadas, numa economia aberta, em modelos macroeconômicos de mercado de trabalho na visão da concorrência monopolística. A busca pela explicação do comportamento dos salários justifica-se na medida em que o salário é um dos mais importantes indicadores da economia, pois contribui diretamente para definir a distribuição da renda e o nível de emprego, refletindo condições de poder real de compra da população em relação direta com a pobreza.

Tabela 3 - Equação sobre o comportamento do salário real nacional, estados brasileiros (1995-2008)

\begin{tabular}{|c|c|}
\hline Variável explicativa & Salário real \\
\hline \multirow{2}{*}{ Produtividade do emprego } & $0,069 * *$ \\
\hline & $(0.03249)$ \\
\hline \multirow{2}{*}{ Emprego $(-1)$} & $-2,9776 * * *$ \\
\hline & $(0,6948)$ \\
\hline \multirow{2}{*}{ Crescimento populacional } & $9.4431 * * *$ \\
\hline & $(2.3920)$ \\
\hline \multirow{2}{*}{ Taxa de câmbio real } & $0,6397^{* * *}$ \\
\hline & $(0,6714)$ \\
\hline Coeficiente de ajustamento & 0,2933 \\
\hline Teste de subidentificação LM $=27,78$ & $P=0,0000$ \\
\hline Teste de Wald de fraca identificação $F=10,19$ & $P=0,1520$ \\
\hline
\end{tabular}


conclusão

\begin{tabular}{l|c}
\hline Variável explicativa & Salário real \\
\hline Teste de superidentificação Sargan $=1.037$ & $\mathrm{P}=0,5956$ \\
\hline Teste de Wooldrige de autocorrelação $\mathrm{F}=48,900$ & $\mathrm{P}=0,0000$ \\
\hline Teste modificado de Wald de heterocedasticidade $\mathrm{chi}^{2}=785,59$ & $\mathrm{P}=0,0000$ \\
\hline Teste de Hausman $\mathrm{Qui}^{2}=62.78$ & $\mathrm{P}=0,0000$ \\
\hline
\end{tabular}

Fonte: Elaboração própria a partir dos resultados da pesquisa.

Nota: Forma Funcional duplo-log. Valores entre parênteses: erro-padrão; - ns - não significativo, ***significativo a 1\%, **significativo a $5 \% \mathrm{e}$ *, significativo a $10 \%$; Instrumentos: $\log (\mathrm{cam}), \log (\mathrm{sal}(-1)), \log (\mathrm{sal}(-2)), \log$ (gsau).

O primeiro resultado importante diz respeito a não confirmação da hipótese de estudo de relação positiva entre crescimento da população e salário real. Para justificar a relação positiva encontrada, é relevante uma análise sucinta da demografia do Brasil. O país vem experimentando transformações na estrutura de sua população, marcadas, sobretudo, pelo processo de transição demográfica, resultado da redução das taxas de mortalidade e aumento da esperança de vida. Segundo dados do IBGE (2009), a parcela da população de adolescentes caiu de $30 \%$ em 1998 para 24,7\% (2008). O contingente populacional de pessoas idosas (acima de 70 anos) vem aumentando. De acordo com dados de 2008, esse grupo representa quase 10 milhões de pessoas no país. De maneira positiva, o envelhecimento populacional traz a perspectiva de um estoque de mão de obra com maior nível educacional e maiores experiências acumuladas que, via de regra, se traduz em melhores índices de produtividade.

Outro destaque é a razão de dependência, ${ }^{5}$ indicador demográfico utilizado na análise socioeconômica, por exemplo, do mercado de trabalho, cujo valor tem mostrado comportamento decrescente ao longo dos anos. Em 2007, a razão entre as populações de 0 a 14 anos e de 65 anos ou mais (população inativa) e o segmento populacional com idades entre 15 a 64 anos de idade (população ativa) era de $47,9 \%$. Na análise dos estados,nesse mesmo ano, a menor razão refere-se à Santa Catarina, 41,4\%, enquanto no Maranhão consta o valor máximo de 66,5\%, uma vez mais indicando significativas desigualdades territoriais, fruto de processos reprodutivos diferenciados.

A redução da razão de dependência está diretamente ligada ao fenômeno de "bônus demográfico" ou "janela de oportunidades". Segundo Alves (2008), a janela ou bônus demográfico no Brasil começou em 1995 e irá até 2055, perfazendo o período de sessenta anos. A maior diferença entre o percentual da População em Idade Ativa (PIA) e da razão de dependência da população de 15 a 64 anos

5 Expressa a proporção de pessoas em idade potencialmente inativa de uma população em relação a 100 pessoas em idade potencialmente ativa ou disponível para as atividades econômicas. 
é de $18,2 \%$, entre2020 e 2025. Este pode ser considerado o quinquênio de maior abertura da janela de oportunidade brasileira, cuja previsão de fechamento se fará a partir de2025 até a perda de todas as vantagens a partir de 2055.

Diante dessas perspectivas, deve-se atuar de maneira preventiva para que esse bônus não se torne ônus. A relação positiva entre crescimento populacional e nível de salários nas unidades federativas mostra que isto não ocorreu no período analisado. A razão é que, mesmo com sistemas de produção mais intensivos em capital, não tem ocorrido queda significativa no nível geral de ocupação. Nesse contexto, as macrodiretrizes das políticas públicas devem estar atentas à "janela de oportunidades" proporcionada pela nova estrutura etária brasileira. No entanto, analisando a área de educação, o planejamento para o aproveitamento do bônus demográfico está atrasado, dado o não aproveitamento de toda a capacidade da população potencialmente produtiva em razão de questões ligadas à defasagem escolar dessa faixa etária. Os policymakers devem se ater às políticas públicas educacionais e afins, de forma a permitir aos estados brasileiros desfrutarem das possibilidades de crescimento econômico relacionadas ao bônus, via maior produtividade do mercado de trabalho, sem que ocorra desperdício desse fenômeno por dificuldades educacionais.

Outra variável da equação 5 com relação positiva com o nível salarial da economia é a produtividade do emprego, conforme previsto pela teoria. No que diz respeito aos anos 1990, deve-se destacar dois importantes aspectos. O primeiro seria os ganhos de produtividade que se deram de maneira muito significativa nesse período. O segundo aspecto é que tais ganhos não foram repassados aos salários reais na mesma magnitude, em função dos efeitos adversos sobre o emprego na indústria em função da terceirização. Daí a justificativa para a resposta positiva dos salários à produtividade.

Tais resultados são corroborados pelo estudo de Romanatto et al. (2008), cujas conclusões empíricas estão embasadas no modelo de concorrência monopolística e indicam que o salário real tem relação de longo prazo positiva com a produtividade e negativa com a taxa de câmbio real. Quando se observa o mercado de trabalho dos anos 2000, os resultados já não são tão satisfatórios. Em conformidade com o Instituto de Pesquisa Econômica Aplicada (2012), de maneira mais agregada, a economia brasileira demonstrou baixo dinamismo em termos de produtividade do trabalho, entre 2000 e 2009, dado o baixo crescimento médio anual da produtividade para o conjunto das atividades da economia, de apenas $0,9 \%$.

Outros estudos, a exemplo de Pereima e Nascimento (2012), apontam transformações recentes no mercado de trabalho alinhadas aos resultados do presente estudo. Segundo os autores, as taxas de crescimento populacional e da PIA estão diminuindo ao longo do tempo, ao passo que o número de pessoal ocupado está aumentando e a taxa de desemprego diminuindo. De maneira positiva, nas duas 
últimas décadas o mercado de trabalho tem absorvido todo o aumento da população em idade ativa, que cresceu $46,8 \%$ nesses anos. Ademais, dado o crescimento da produtividade ligado ao aumento do PIB brasileiro, observa-se que o mercado de trabalho nacional tem obtido sucesso em seus problemas históricos, dando significativos passos na absorção de mão de obra e no nível pleno de emprego.

Por fim, destaca-se a relação negativa entre câmbio real e salários reais, respaldada na visão das apreciações do câmbio associadas às elevações de salários, bem como desvalorizações cambiais ligadas a perdas salariais. No período de análise, a conjuntura de aumento das importações também subsidia essa relação encontrada. O câmbio favorável às importações contribuiu para a introdução de novas tecnologias e posteriores aumentos de produtividade e, por consequência, possibilitou maior demanda por mão de obra melhor preparada para operar novas tecnologias, tendo como resultado final os ganhos salariais. Além disso, nota-se que no período a taxa de câmbio mais baixa contribuiu para a estabilidade da moeda e, consequentemente, favoreceu o salário real (CRUZ et al., 2010).

Bresser-Pereira e Gala (2008) alertam que são desejáveis os aumentos de salários ligados às reduções dos juros, aluguéis e lucros especulativos, ao contrário dos aumentos salariais artificiais por intermédio da sobrevalorização da taxa de câmbio, que não são bem-vindos. Se pensada a sobrevalorização cambial sob o ângulo da demanda, a insuficiência de demanda ligada à excessiva apreciação da moeda pode causar aumento do desemprego. Os acréscimos artificiais dos salários levarão a quedas do emprego e da renda, uma vez que a produção necessária para atender a esta demanda virá do exterior, na forma de importações. Observa-se, nessas circunstâncias, que a diminuição das exportações reduzirá as oportunidades de investimento ou das expectativas de lucro.

O próximo passo é avaliar a importância da educação, da saúde, do capital físico e da produtividade da mão de obra como insumos importantes para permitir que o cidadão brasileiro usufrua de aumentos da renda per capita. Tal discussão toma por base os parâmetros estimados da sexta equação do sistema listados na Tabela 4. 
Tabela 4 - Efeito do estoque de infraestrutura física e capital humano sobre a renda per capita dos estados brasileiros (1995-2008)

\begin{tabular}{l|c}
\hline Variável explicativa & PIB per capita \\
\hline Educação & $\begin{array}{c}\mathbf{0 , 9 8 8 3} \\
(0,5355)\end{array}$ \\
\hline Rodovias & $\begin{array}{c}\mathbf{0 , 3 8 9 4} \\
(0,1739)\end{array}$ \\
\hline Mortalidade Infantil & $\mathbf{- 0 , 3 6 8 \mathbf { * } ^ { * * }}$ \\
\hline Produtividade do emprego & $(0,1850)$ \\
\hline Coeficiente de determinação $\left(\mathrm{R}^{2}\right)$ & $\mathbf{0 , 0 8 7 6 ^ { * }}$ \\
\hline Teste de subidentificação LM $=11,388$ & $0,0496)$ \\
\hline Teste de Wald de fraca identificação $\mathrm{F}=4,30$ & $\mathrm{P}=0,0098$ \\
\hline Teste de Wooldrige de autocorrelação $\mathrm{F}=40,612$ & $\mathrm{P}=0,0000$ \\
\hline Teste modificado de Wald de heterocedasticidade chi ${ }^{2}=2430,85$ & $\mathrm{P}=0,0000$ \\
\hline Teste de Hausman chi ${ }^{2}=107,32$ & $\mathrm{P}=0,0000$ \\
\hline
\end{tabular}

Fonte: Elaboração própria a partir dos resultados da pesquisa.

Nota: Forma Funcional duplo - log. Valores entre parênteses: erro-padrão; - ns - não significativo, "* "significativo a $1 \%$, " "significativo a $5 \%$ e ", significativo a $10 \%$; Instrumentos: $\log (\operatorname{PIB}(-1)), \log (\operatorname{cresc}(-1)), \log (\operatorname{pib}(-4)), \log (\operatorname{cresc})-2)), \log (\operatorname{grod}(-1))$.

Primeiramente, frente à significância estatística e à confirmação dos sinais esperados para cada coeficiente, pode-se afirmar que contribuem positivamente para o aumento da renda per capita estadual o maior acesso à educação, a redução da mortalidade infantil, as melhorias na infraestrutura rodoviária e o aumento da produtividade do emprego. Confirma-se também a premissa de que os estoques de capital físico e humano constituem insumos produtivos dos estados, ao passo que estes permitem o aumento do produto per capita, em todos os estados brasileiros, no período analisado.

Diante do exposto, vale retomar os primeiros resultados que confirmam a eficácia dos gastos estaduais em educação e cultura, bem como em saúde e em transporte rodoviário, quanto aos aprimoramentos na educação, na saúde e na condição das rodovias, respectivamente. Considerando que essas categorias de capital mostram-se primordiais para a promoção do crescimento econômico traduzido em aumento da renda per capita (Tabela 4), estabelece-se a relação positiva, embora indireta, entre gastos públicos nestes ativos e sua capacidade de 
promoção do crescimento econômico das unidades federativas brasileiras, entre 1995 e 2008.

Ademais, as elasticidades PIB per capita indicam que acréscimos na escolaridade do brasileiro permitem maior impacto sobre o comportamento da renda per capita estadual. De acordo com o coeficiente, dado o aumento de gasto público que permita a variação de dez pontos percentuais nos anos de estudo, tem-se a possibilidade de aumento da renda per capita em 9,8\%. As reduções nas taxas de mortalidade e a melhoria das rodovias mediante atuação dos governos estaduais apontam resultados benéficos próximos. No caso da possibilidade das despesas com saúde reduzirem o indicador de mortalidade infantil em 10\%, o aumento do PIB per capita é de 3,6\%, enquanto que o aumento de rodovias pavimentadas permitiria a alta de 3,89\% na renda per capita. A seguir, de modo a fazer inferência sobre indicadores econômicos importantes para explicar a pobreza nos estados, é apresentada a Tabela 5.

Tabela 5 - Efeito indireto dos gastos públicos em infraestrutura física e em capital humano sobre a pobreza nos estados brasileiros (1995-2008)

\begin{tabular}{l|c}
\hline Variável explicativa & $\begin{array}{c}\text { Número de } \\
\text { pobres }\end{array}$ \\
\hline Índice de Gini de Concentração de renda & $\begin{array}{c}2,2464 * * \\
(0,3163)\end{array}$ \\
\hline Produto Interno Bruto per capita & $-0,4232^{* * *}$ \\
\hline Produtividade do emprego & $-0,2002)$ \\
\hline Crescimento populacional & $(0,0696)$ \\
\hline Coeficiente de determinação $\left(\mathrm{R}^{2}\right)$ & $-34,5883^{* *}$ \\
\hline Teste de subidentificação LM $=59,91$ & $(6,9931)$ \\
\hline Teste de Wald de fraca identificação $\mathrm{F}=36,89$ & 0,5527 \\
\hline Teste de Wooldrige de autocorrelação $\mathrm{F}=40,612$ & $\mathrm{P}=0,0000$ \\
\hline Teste modificado de Wald de heterocedasticidade chi ${ }^{2}=2430,85$ & $\mathrm{P}=0,0010$ \\
\hline
\end{tabular}

Fonte: Elaboração própria a partir dos resultados da pesquisa.

Nota: Forma Funcional linear. Valores entre parênteses: erro-padrão; Teste de Hausman Qui2 = Não conclusivo; - ns - não significativo, "** significativo a 1\%, "*significativo a $5 \% \mathrm{e}$ *, significativo a 10\%; Instrumentos: pobre (-1), pobre $(-3)$, cresc $(-2)$, cresc $(-3)$.

De acordo com a estimação, a concentração de renda age de maneira a agravar as condições de pobreza dos estados brasileiros, dado o coeficiente posi- 
tivo para a variável exógena de concentração de renda (índice de Gini). No que concerne à relação direta entre desigualdade de renda e intensidade da pobreza, conforme discutido sobre as raízes da pobreza ligada ao critério da renda, a distribuição desigual dos recursos atua agravando o cenário de pobreza, considerando a realidade de cada um dos estados. A meta máxima de equidade social tem sido alcançada quando observada a realidade do país como um todo, mas as desigualdades quanto à distribuição de renda intra e interestaduais ainda firmam-se como obstáculos ao processo de crescimento com inclusão social.

Sobre a desigualdade interestadual, os estados nordestinos, em sua maioria, são os mais desiguais, com índices superiores à média nacional $(0,59)$. Os destaques são para o Piauí e a Paraíba, com índices de Gini de 0,610 e 0,609, respectivamente. Por outro lado, a região Sul não mostra alta concentração de renda, a exemplo de Santa Catarina $(0,508)$. No Sudeste, os estados possuem relativamente o mesmo perfil, haja vista o índice para o Rio de Janeiro de 0,569 e para Minas Gerais, na casa de 0,566. Por sua vez, o estado paulista aponta índice de 0,532, inferior, portanto à média nacional.

No que concerne à relação direta entre taxa de crescimento populacional e o número de pessoas abaixo da linha de pobreza, uma negativa da hipótese definida, cabe remeter a uma importante questão. A ideia é de que o crescimento da população possa agravar as condições de subsistência da sociedade, se o crescimento da demanda de emprego da economia for insuficiente para atender ao excesso de mão de obra. No Brasil, a população vem crescendo a taxas menores, desde os anos oitenta. Ademais, o mercado de trabalho tem conseguido absorver a força de trabalho existente, mas enfrenta, por vezes, problemas ligados ao perfil desses trabalhadores, os quais, às vezes, não atendem às exigências dos cargos.

É notório que, apesar do grande contingente populacional ainda não inserido na economia formal e vivendo em condições de pobreza, até mesmo os setores com baixa produtividade de emprego, como as atividades ligadas à construção civil, não preenchem a demanda e o resultado são os aumentos salariais. Novamente, fica registrada a necessidade de políticas complementares de qualificação da força de trabalho, como meio de elevar a produtividade desses indivíduos para que possam ter oportunidade de ingresso no mercado de trabalho nacional.

Dito isso, insere-se a importância de outro resultado que é o estabelecimento da relação inversa entre a produtividade do trabalho e o número de brasileiros com renda abaixo da linha de pobreza, confirmando a hipótese inicialmente estabelecida. Conforme exposto, diante das condições atuais do mercado de trabalho brasileiro, aquele indivíduo com produtividade mais elevada tem maior probabilidade de inserção no mercado de trabalho, com vistas a ter rendimentos que lhe permitam sair da condição de pobreza. Esse resultado vai ao encontro do estabe- 
lecido na equação estimada sobre as variáveis que influenciam a renda per capita, a exemplo da produtividade do emprego.

Fica evidente, portanto, a existência de uma relação direta e indireta entre aumento da produtividade e queda da pobreza nos estados brasileiros. O efeito indireto fica confirmado, considerando-se o crescimento do PIB per capita estadual, no período de análise, acompanhado da redução da pobreza no país, como atesta a definição do coeficiente negativo e estatisticamente significativo da variável PIB per capita na equação sobre a pobreza (Tabela 5). A inclusão da variável PIB per capita na equação de pobreza tem como propósito identificar se o crescimento econômico nos estados brasileiros, no período analisado, teria características do tipo pró-pobre, ou seja, se o crescimento econômico tenderia a favorecer os mais pobres, gerando, endogenamente, redução da pobreza. O que se observa é que apesar dos 21 milhões de brasileiros pobres concentrados, sobremaneira, no Nordeste, houve crescimento da renda per capita acompanhado de queda na pobreza, consideradas as divergências de estrutura socioeconômica dos estados.

Em suma, confirma-se que os gastos públicos em educação, saúde e em transporte rodoviário são responsáveis pelos avanços nessas categorias de capital físico e humano (equações 1 a 3). Ademais, ficou confirmado que a escolaridade, a melhoria na saúde da população e na infraestrutura rodoviária promovem expansão da renda per capita dos estados, esta última relacionada inversamente ao patamar de pobreza vigente nas unidades federativas. Logo, os resultados do sistema proposto permitem dizer que essas categorias de despesas dos governos contribuíram para a queda no número de pessoas que vivem com renda mensal inferior à linha de pobreza, durante os anos de 1995-2008, em cada um dos estados da federação.

\section{Considerações Finais}

Diante dos objetivos propostos neste estudo, fica atestada a eficácia dos dispêndios públicos em infraestrutura rodoviária e em educação e saúde quanto aos avanços na malha rodoviária e no estoque de capital humano, respectivamente, a partir da análise da estrutura socioeconômica dos estados brasileiros. Tal resultado corrobora o verificado por Cruz et al. (2010) para o Brasil como um todo.

A análise confirma que a escolaridade média dos estados, assim como os avanços na infraestrutura rodoviária e melhores condições de saúde mostraram-se importantes para elevar a renda per capita dos estados. Da mesma forma, comprovou-se a importância da produtividade do emprego para o crescimento da economia de cada uma das federações brasileiras. Ficou atestado, portanto, que os governos federal e estadual, por meio das políticas de dispêndios nessas categorias, atingiram a meta de fazer a economia crescer com benefícios também à par- 
cela da população que se encontrava em condição de pobreza. Posto isso, pode-se afirmar que, ainda que de forma indireta, os gastos públicos nessas categorias econômicas constituem medidas eficazes para implantar um modelo de crescimento com desenvolvimento com inclusão social, ou seja, o crescimento econômico pró-pobre. Apesar do questionamento da efetividade desse tipo de política quando analisadas as estruturas de cada estado brasileiro, comprovou-se a superioridade dos investimentos voltados ao aprimoramento do estoque de capital humano com ênfase na educação. Essa forma de agregar ao capital social constitui medida efetiva no combate à pobreza, considerando seus efeitos positivos sobre a renda per capita estadual e sobre o dinamismo o mercado de trabalho, por meio de geração de postos de emprego.

É importante atentar também que as políticas de gasto social pautadas em concessão de benefícios financeiros estão vinculadas ao cumprimento de condicionalidades de serviços básicos de educação e saúde. No entanto, apesar dos resultados positivos, sobretudo de curto prazo desse tipo de instrumento político, a renda é instrumento de obtenção de capacidades, mas não o fim. A proposta de ligar o recebimento do benefício mensal ao acesso a itens de capital social é de grande mérito, pois permite elevar o potencial da população pobre de obter renda, ou seja, oferece possibilidade aos pobres de se libertarem da pobreza medida essencialmente pela renda. No entanto, tais políticas trazem à tona outra problemática: a dificuldade de permitir aos mais pobres desfrutarem dos resultados positivos do processo de crescimento econômico. A verdade é que os retornos aos ativos, a exemplo da educação, dependem, fortemente, da provisão de ativos públicos complementares como, por exemplo, infraestrutura escolar e qualidade de ensino. Entretanto, em grande parte do Brasil, os cidadãos pobres têm acesso ao ensino de baixa qualidade e com isso os retornos à educação são, relativamente, mais baixos para esses indivíduos. A priori, não estando preparada para o mercado de trabalho, essa parcela da população tem reduzida sua probabilidade de acumulação de capital humano e de mobilidade social, fatores essenciais para o crescimento e alívio da pobreza nacional, conforme atesta este estudo.

Outro agravante é o fato de o século XXI apresentar-se como o tempo das inovações, da valorização do conhecimento, de modo que a constante revolução na fronteira tecnológica provoca aumento da demanda por trabalhadores mais qualificados. Desse modo, retirar a parcela da população da condição de pobreza estritamente ligada à renda não soluciona o entrave relacionado à possibilidade de aumento dos rendimentos dos trabalhadores mais qualificados para a inovação tecnológica, o que aumenta o hiato de salários entre estes e os não qualificados (grande parte, indivíduos pobres). Logo, a parcela de indivíduos que sai do status de "pobre" atrelado ao conceito de linha de pobreza não se integra, efetivamente, ao mercado de trabalho e à dinâmica sociedade de consumo, o que acaba 
por agravar a desigualdade social no Brasil. Surgem, então, outros obstáculos aos formuladores de políticas relacionados ao desafio de atenuar a distorção gerada por esse tipo de instrumento de crescimento, realçando a importância da atuação do Estado em outras instâncias, por meio de outros tipos de políticas públicas que permitam implantar, efetivamente, o crescimento do tipo pró-pobre.

\section{Referências}

BARROS, R. P. et al. A importância da queda recente da desigualdade na redução da pobreza. Brasília, DF: Ipea, 2007. (Texto para discussão, n. 1256).

BIASOTO JÚNIOR. Atenção básica e emprego em saúde: alguns elementos e potencialidades. Tempus Actas de Saúde Coletiva, v. 1, n. 1, p. 17-31, 2007.

BLACKBURN, K.; HUNG, V. T. Y.; POZZOLO, A. F. Research, development and human capital accumulation. Journal of Macroeconomics, v. 22, n. 2, p. 189-206, Spring 2000.

BOURGUIGNON, F. The growth elasticity of poverty reduction; explaining heterogeneity across countries and time periods. In: EICHER,T.; TURNOVSKY,S. (Ed.). Inequality and growth. Theory and policy implications. Cambridge: The MIT Press, 2003.

BRADSHAW, J.; FINCH, N. Overlaps in dimensions of poverty. Journal of Social Policy, v. 32, n. 4, p. 513-525, 2003.

BRASIL. Ministério da Fazenda. Tesouro Nacional. Sistema Integrado de Administração Financeira do Governo Federal. Disponível em: < http://www.tesouro.fazenda.gov.br/ estatistica/est_contabil.asp>. Acesso em: 04 jan. 2013.

. Ministério dos Transportes. Agência Nacional dos Transportes Terrestre. Anuário Estatístico dos Transportes Terrestres. Disponível em: <http://appweb2.antt.gov.br/ InformacoesTecnicas/aett/aett_2009/principal.asp> . Acesso em: 10 nov. 2012.

BRESSER-PEREIRA, L. C.; GALA, P. Foreign savings, insufficiency of demand, and low growth. Journal of Post Keynesian Economics, v. 30, n.3, p. 315-334, 2008.

CONFERENACIA NACIONAL DOS TRANSPORTES. Pesquisa CNT de rodovias 2012: relatório gerencial. Brasília, DF: CNT; SEST; SENAT, 2012. 408 p.

CRUZ, A. C.; TEIXEIRA, E. C.; BRAGA, M. J. O efeito dos gastos públicos em infraestrutura e em capital humano no crescimento econômico e na redução da pobreza no Brasil. Economia, v. 11, p. 163-185, 2010.

FAN, S.; CHAN-KANG, C. Road development, economic growth, and poverty reduction in China. Research Report, n. 138, 2005. Disponível em: < https://pdfs.semanticscholar.org/fb08/ 7bcce486437379dbe619576cc551726b19c6.pdf>. Acesso em: 28 nov. 2012.

FAN, S.; ZHANG, L.; ZHANG, X. Growth, inequality, and poverty in rural China: the role of public investments. Washington, D. C.: Intl Food Policy Res Inst, 2002. 
FERREIRA, A. B.; NAKABASHI, L.; SANTOS, M. Crescimento econômico e acumulação de capital humano: uma análise de causalidade. Belo Horizonte: UFMG/CEDEPLAR, 2003. (Texto para Discussão, n. 222).

FOSTER, A.D.; ROSENZWEIG, M.R. Technical change and human-capital returns and investments: evidence from the green revolution. The American Economic Review, v. 86, n. 4, p. 931-953, 1996.

GREENE, W. Econometric Analysis.5rd. New York: Macmillan, 2002. 1026p.

GUAN, W. From the help desk: bootstrapped standard errors. The Stata Journal, v. 3, n. 1, p. 71-80, 2003. Disponível em: <http://www.stata-journal.com/sjpdf.html?articlenum=st0034>. Acesso em: 15 jan. 2013.

GUJARATI, D. N. Econometria Básica. Rio de Janeiro: Editora Campus, 2006. 812 p.

HAGENAARS, A.; DE VOS, K. The definition and measurement of poverty. The Journal of Human Resources, v. 23, n. 2, p. 211-221, 1988.

HANSEN, L. P. Large sample properties of generalized method of moments estimators. Econometrica, v. 50, n. 4, p. 1029-54, 1982.

HAUSMAN, J. A. Specification tests in econometrics. Econometrica, v. 46, n. 5, p.1251-1271, Sept. 1978.

IBGE. Pesquisa Nacional por Amostra de Domicílios. 2008. Disponível em: < http://www.ibge. gov.br/home/estatistica/populacao/trabalhoerendimento/pnad2008>. Acesso em: 07 nov. 2012.

. Síntese de Indicadores Sociais. 2009. Disponível em: < http://www.ibge.gov.br/home/ estatistica/populacao/condicaodevida/indicadoresminimos/sinteseindicsociais2009/default_ tab.shtm>. Acesso em: 07 nov. 2012.

INSTITUTO DE PESQUISA ECONÔMICA APLICADA. Produtividade no Brasil nos anos 2000-2009: análise das contas nacionais. Brasília, DF: Ipea, 2012. (Comunicados do IPEA, n. 133). Disponível em: <http://www.ipea.gov.br/portal/images/stories/PDFs/ comunicado/120203_comunicadoipea133.pdf>. Acesso em: 15 nov. 2012.

IPEADATA. Disponível em: < http://www.ipeadata.gov.br/Default.aspx> $>$. Acesso em: 30 out. 2012.

KAKWANI, N.; PERNIA, E. What is pro-poor growth? Asian Development Review, v. 16, n. 1, p. 1-16, 2000. Disponível em: <http://www.policyinnovations.org/ideas/policy_library/ data/01158/_res/id=sa_File1 $>$. Acesso em: 10 nov. 2012;

LOPEZ. H. Macroeconomics and inequality. Washington, D.C.: The World Bank, 2013. (World Bank's PREM Poverty Group - MPR).

. Pro-poor-pro-growth: is there a trade off? Washington, D.C.: The World Bank, Policy

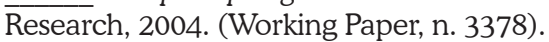

MANSO, C. A.; BARRETO, F. A. Rebatimento regionais de bem-estar social no Brasil: considerações a partir dos ciclos econômicos da renda nacional e da estrutura do mercado 
de trabalho. Fortaleza: Laboratório de Estudos da Pobreza/CAEN/UFC, maio 2009, (Ensaio sobre Pobreza, 19). Disponível em: <http://www.caen.ufc.br/attachments/article/113/esp19. pdf > . Acesso em: 10 set. 2012.

PEREIMA, J. B.; NASCIMENTO, R. Crescimento, emprego e renda no Brasil: rumo ao pleno emprego produtivo. Revista Economia 8 Tecnologia, v. 8, n. 2, p. 61-80, 2012.

RAM, R. Government size and economic growth: a new framework and some evidence from cross-section and time-series data. American Economic Review, v. 76, n. 1, p. 191-203, 1986.

RAVALLION, M.; CHEN, S. Measuring pro-poor growth. Economic Letters, v. 78, n.1, p. 9399, 2003.

RIGOTTO, M. E.; SOUZA, N. J. Evolução da educação no Brasil, 1970-2003. Análise, v.16, n. 2, p. 339-358, 2005.

ROMANATTO, E.; PORCILE, G.; CURADO, M. Produtividade, salários e taxa de câmbio: uma análise da experiência brasileira nos anos 1990. Revista de Economia Contemporânea, v. 12, n. 3, p. 545-570, 2008.

SEN, A. Development: which way now? The Economic Journal, v. 93, n. 372, p. 745-762, 1983.

SILVA, G. J. C.; JAYME JUNIOR, F. G.; MARTINS, R. S. Gasto público com infraestrutura de transporte e crescimento: uma análise para os estados brasileiros (1986-2003). Economia 8 Tecnologia, ano5, v. 16, p.53-66, jan./mar. 2009.

WHITE, H.; ANDERSON, A. Growth versus redistribution: does the pattern of growth matter? Development Policy Review, v. 19, n. 3, p. 267-289, Sept. 2000.

Recebido em: 23/05/2015. Aceito em: 11/08/2015. 